\title{
Blood vessel ultrastructural picture in a CADASIL patient diagnosed at an advanced age
}

\author{
Eliza Lewandowskaํㅜ Paulina Felczak ${ }^{1}$, Julia Buczek², Karolina Gramza ${ }^{3}$, Janina Rafałowska ${ }^{4}$ \\ ${ }^{1}$ Department of Neuropathology, Institute of Psychiatry and Neurology, Warsaw, ${ }^{2}$ Department of Neurology, Institute of Psychiatry \\ and Neurology, Warsaw, ${ }^{3}$ Neuroimmunology Laboratory at the $2^{\text {nd }}$ Department of Neurology, Institute of Psychiatry and Neurology, \\ Warsaw, ${ }^{4}$ Department of Experimental and Clinical Neuropathology, Mossakowski Medical Research Institute, Polish Academy of \\ Sciences, Warsaw, Poland
}

\begin{abstract}
We report the case of an 84-year-old male patient afflicted by cerebral autosomal dominant arteriopathy with subcortical infarcts and leukoencephalopathy (CADASIL) showing minimal symptoms of disease. The patient was diagnosed on the basis of ultrastructural and genetic examinations. Ultrastructurally, a typical vascular pathology was found. However, in abnormal capillary vessel walls no granular osmiophilic material (GOM) was found. In the arteriole there were only a few GOM deposits that revealed various structures, of which only some resembled typical round GOM. The arteriolar walls showed severe damage, including fragmentation, degeneration and loss of vascular smooth muscle cells (VSMCs) with numerous deposits of elastin, mucosubstances, different granular debris, as well as collagen fibres in the basement membrane. Lysosomal inclusions with fingerprint morphology, atypical for CADASIL, were located in some of the VSMCs. Very old age at the onset of the disease may suggest that morphological changes in blood vessels, described in this report, may be due to both the disease and the patient's age. To our best knowledge it is the first description of pathology of blood vessels and GOM morphology in a CADASIL patient diagnosed at an advanced age.
\end{abstract}

Key words: CADASIL, morphology of GOM deposits, aging, ultrastructure.

\section{Introduction}

Cerebral autosomal dominant arteriopathy with subcortical infarcts and leukoencephalopathy (CADASIL) is hereditary systemic vascular disease caused by mutations in the NOTCH3 gene. Clinically CADASIL is characterized by migraine, recurrent ischaemic events, dementia, depression and less commonly epileptic seizures [7]. These symptoms usually occur in the fourth or fifth decade of life. However, a few cases of CADASIL diagnosed in a person beyond the age of 20 and even in a 3-year-old child [1,5,10-12] or in the elderly $[15,19]$ have been described.

Degeneration and loss of vascular smooth muscle cells (VSMCs) or pericytes, thickening of basement membrane and the presence of granular osmiophilic material (GOM) deposits are typical vascular changes in CADASIL [8,22]. Granular osmiophilic material deposits, a specific diagnostic feature of CADASIL, 
along with the genetic analysis of the NOTCH3 gene, permit the diagnosis of this disease.

The youngest patient in whom GOM deposits were found was 19 years old [13]. A single and inaccurate case report, describing vascular pathology in a patient with the onset of CADASIL symptoms at a very late age, has been published, but the data on the presence and morphology of GOM deposits are incomplete because the diagnosis was made on the basis of genetic testing only [19].

In this report we present an ultrastructural examination of vascular changes with particular regard to GOM deposits in the skin and skeletal muscle biopsies in an 84-year-old patient with minimal symptoms of CADASIL.

\section{Case report}

An 84-year-old patient was admitted to the Department of Neurology, because his son at the age of 58 was diagnosed with CADASIL (described elsewhere) [17] previously under the care of the Outpatient Clinic of Neurology. The patient has suffered from hypertension for many years. At the age of 67 he had a heart attack, and at the age of 79 the first epileptic seizures occurred. At that time he had a computed tomography (CT) scan of the brain, which showed multiple ischaemic lesions and leukoaraiosis in both hemispheres, as well as moderate

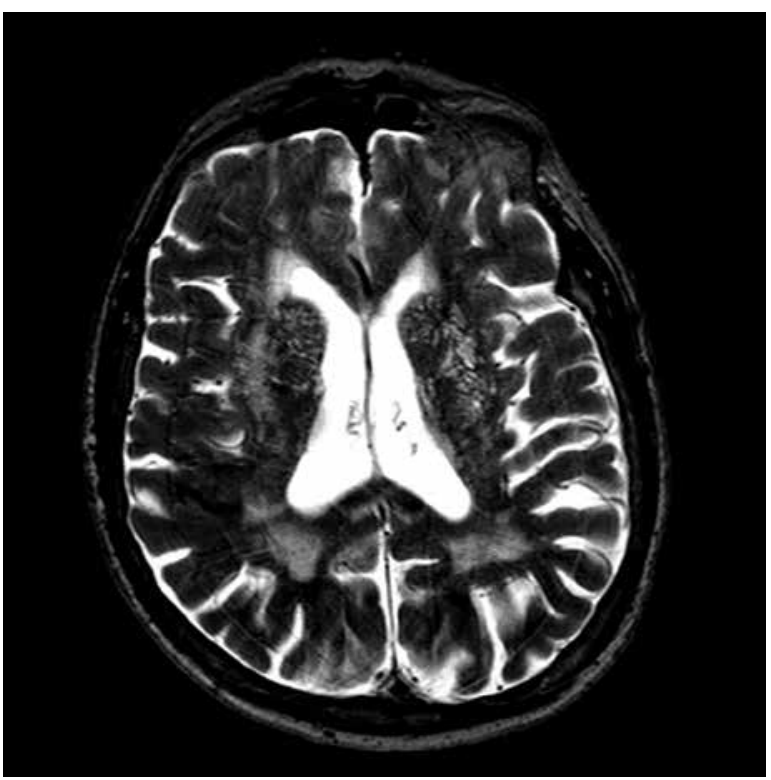

Fig. 1. Axial T2 weighted MR image shows hyperintense signal of bilateral external capsules and periventricular white matter. atrophy of the brain and cerebellum. Treatment with anti-epileptics drugs was started after admission. Epileptic seizures recurred sporadically. His family history revealed that his mother died at the age of 62 due to heart disease; she was also under psychiatric care probably due to depression. His father's medical history was not known. The patient has no siblings. His granddaughter suffered from epilepsy and migraine headaches; she did not decide to be tested for CADASIL.

On neurological examination only small asymmetry of the face was revealed. Neuropsychological evaluation showed normal cognitive function. A magnetic resonance imaging (MRI) scan of the brain revealed widespread lesions in the bilateral periventricular and subcortical white matter, external capsules and significant brain atrophy (Fig. 1). By sequencing of exon 12 of the NOTCH3 gene, the same mutation that was detected previously in the patient's son was identified. To date, the patient remains stable and is independent in activities of daily living.

\section{Material and methods}

The samples of skin and muscle biopsy were fixed in $2.5 \%$ glutaraldehyde and post-fixed in $2 \%$ osmium tetroxide. After dehydration, tissue samples were embedded in epoxy resin. Semithin sections stained with toluidine blue were examined in the light microscope to select blood vessels. Ultrathin sections were counterstained with uranyl acetate and lead citrate and examined with a transmission electron microscope (Opton DPS 109).

\section{Results}

The capillaries in the skin and muscle biopsies were characterized by very thickened basement membrane and degenerated mural cells, pericytes in particular, but they did not contain any GOM deposits (Fig. 2A). In the extreme state only clusters of thickened basement membrane with debris of degenerated mural cells were noted (Fig. 2B).

In the muscle and skin biopsies only a few arterioles were found. They revealed typical features of CADASIL vessels, as well as damage to endothelial cells, degeneration and loss of VSMC thickening of the basement membrane, but only a few GOM deposits varied in electron density. Endothelial cells were often irregular in shape with clear vacuoles 

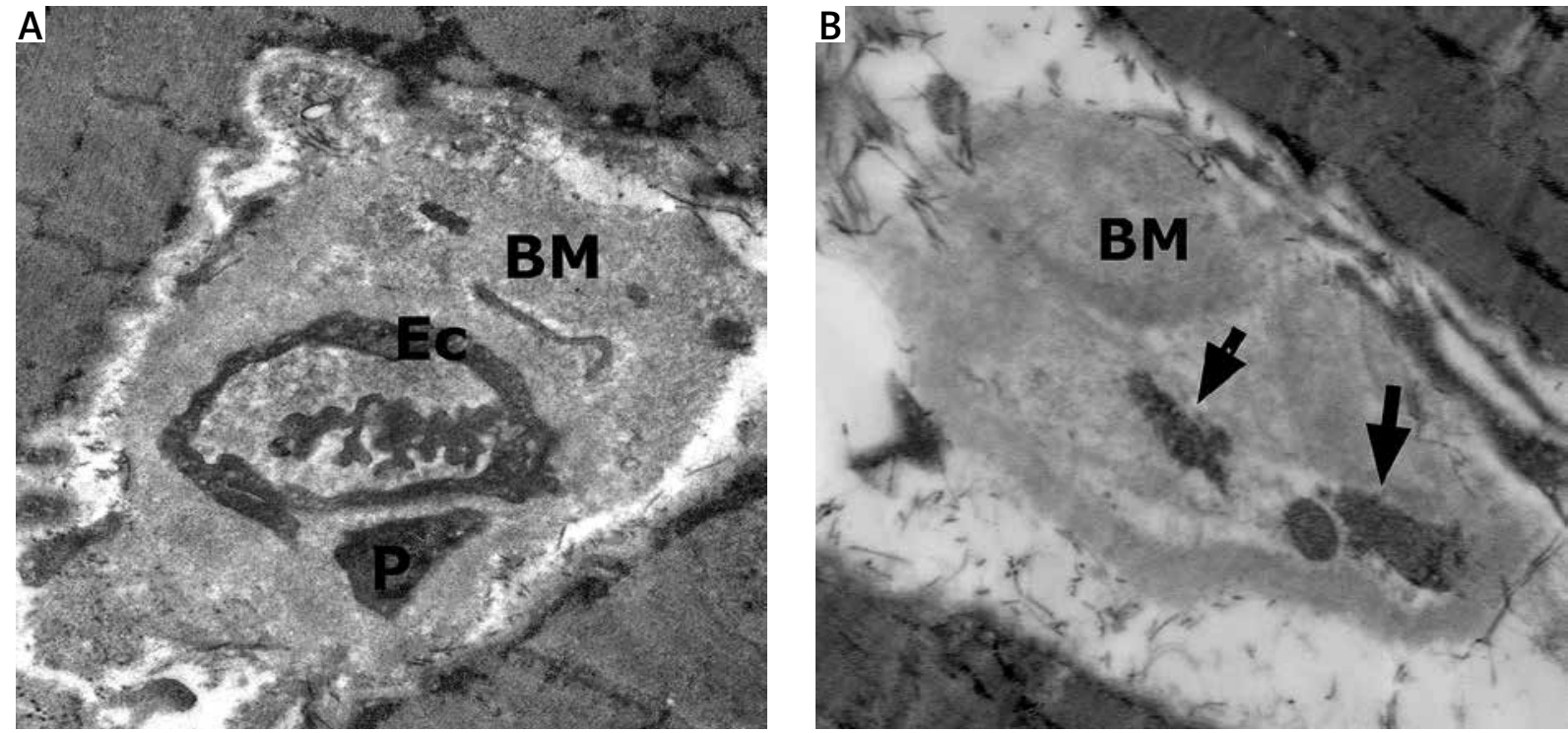

Fig. 2. Degenerative changes in capillary vessels. A) Thickened basement membrane (BM), thin endothelial cells $(E c)$ and disappearing pericytes $(P)$. Orig. magn. $\times 4400$. B) Cluster of thickened basement membrane $(\mathrm{BM})$ with debris of disappearing mural cells (arrows). Orig. magn. $\times 4400$.

of different sizes, dense mitochondria and sometimes numerous microfilaments in the cytoplasm. They formed characteristic thin sharp projections towards/in the direction of VSMCS. Some of these cells were arranged perpendicularly to the lumen of the vessel (Fig. 3).

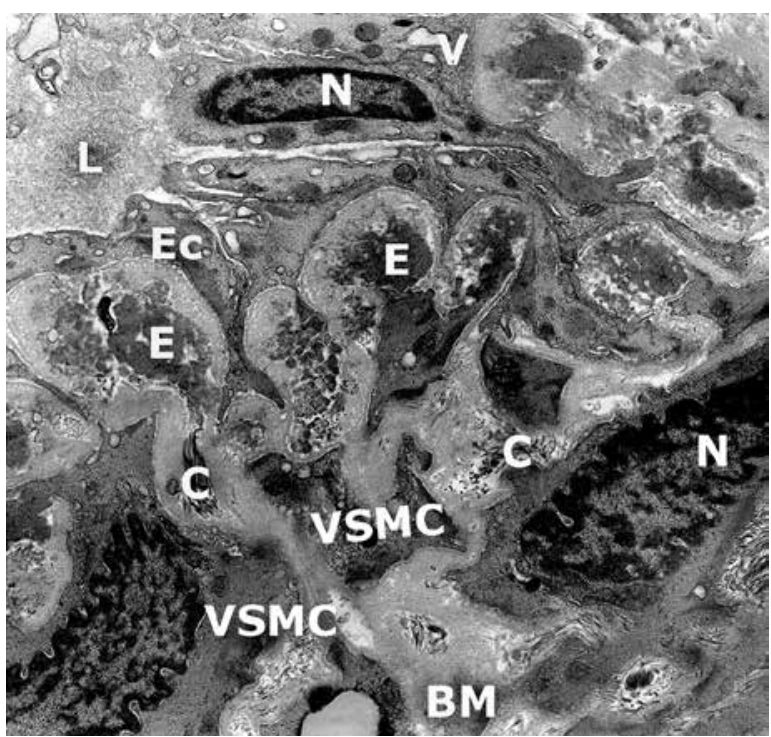

Fig. 3. Arteriolar wall. Endothelial cells (Ec) with vacuoles (V). Vascular smooth muscle cells (VSMC) with different size and shape and misshapen nuclei $(\mathrm{N})$. Basement membrane (BM) with clusters of collagen $(\mathrm{C})$, elastin (E). Lumen (L). Orig. magn. $\times 7000$.
Granular osmiophilic material deposits were located in the indentation of VSMCs (Fig. 4). The majority of them were round or oval and composed of typical electron-dense granules (Fig. 5A), but other deposits demonstrated a lower electron density of granules and irregular shape (Fig. 5B) or blurred gran-

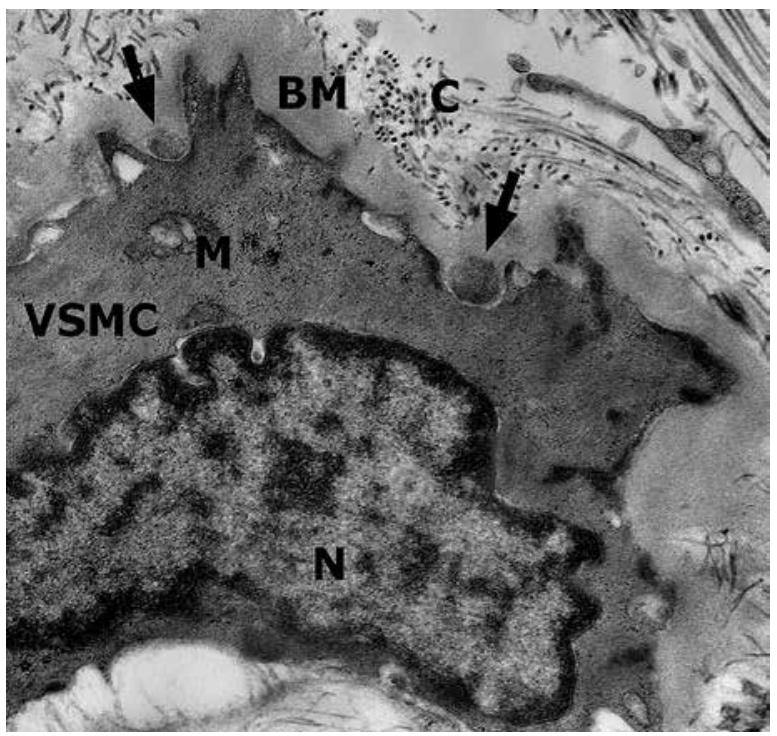

Fig. 4. Granular osmiophilic material deposits (arrows) in vascular smooth muscle cell (VSMC) infolding. Nucleus (N), swollen mitochondrium (M), basement membrane (BM), collagen (C). Orig. magn. $\times 7000$. 

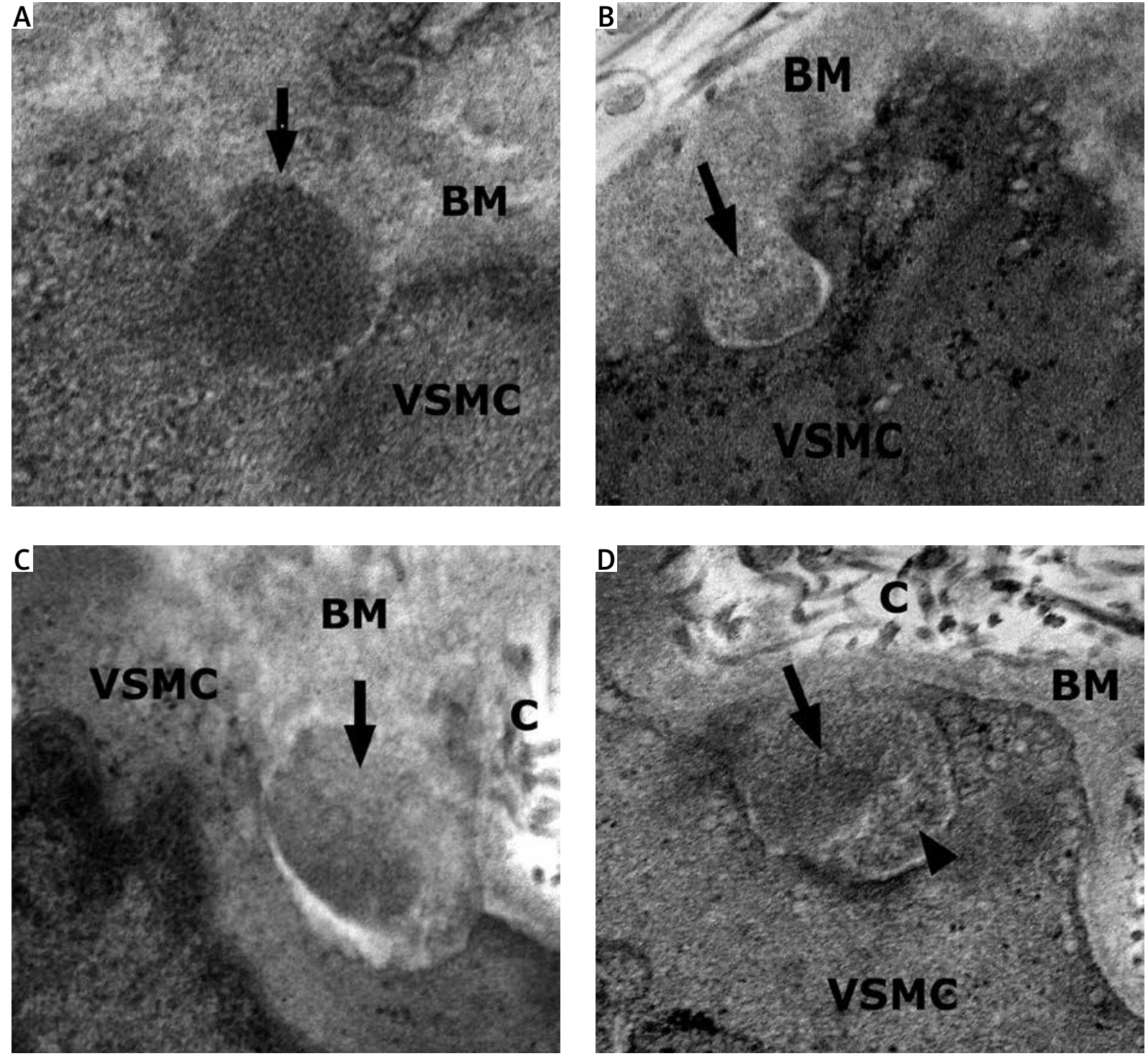

Fig. 5. Different morphology of GOM deposits (arrows) in arteriolar walls. A) GOM (arrow) with typical granular structure and electron density. Basement membrane (BM), vascular smooth muscle cell (VSMC). Orig. magn. $\times 12$ 000. B) GOM (arrow) with different electron density and bizarre shape. Orig. magn. $\times 12000$. C) GOM (arrow) with blurred structure and density similar to basement membrane (BM). Collagen (C). Orig. magn. $\times 12$ 000. D) GOM-like with heterogeneous structure: granular (arrow) and filamentous (arrowhead). Collagen (C). Orig. magn. $\times 12000$.

ular structure (GOM-like). However, their shape and location resembled GOM (Fig. 5C). GOM or "GOMlike" deposits comprising two different parts, granular or filamentous, sometimes difficult to identify, were also present (Fig. 5D). In the same arteriole, the ultrastructural picture of VSMCs was widely different. The majority of VSMCs were irregular in shape, shrunken, and fragmented, with a small diameter; however, large cells were also visible (Fig. 6). They were loosely arranged and separated from neighbouring cells by basement membrane (Fig. 3, 6). In their cytoplasm different numbers of organelles including vacuoles of various size, clusters of glycogen, lipofuscin granules and mitochondria were visible (Fig. 6, 7A). Individual VSMCs in the same arteriole revealed different numbers of mitochondria. 


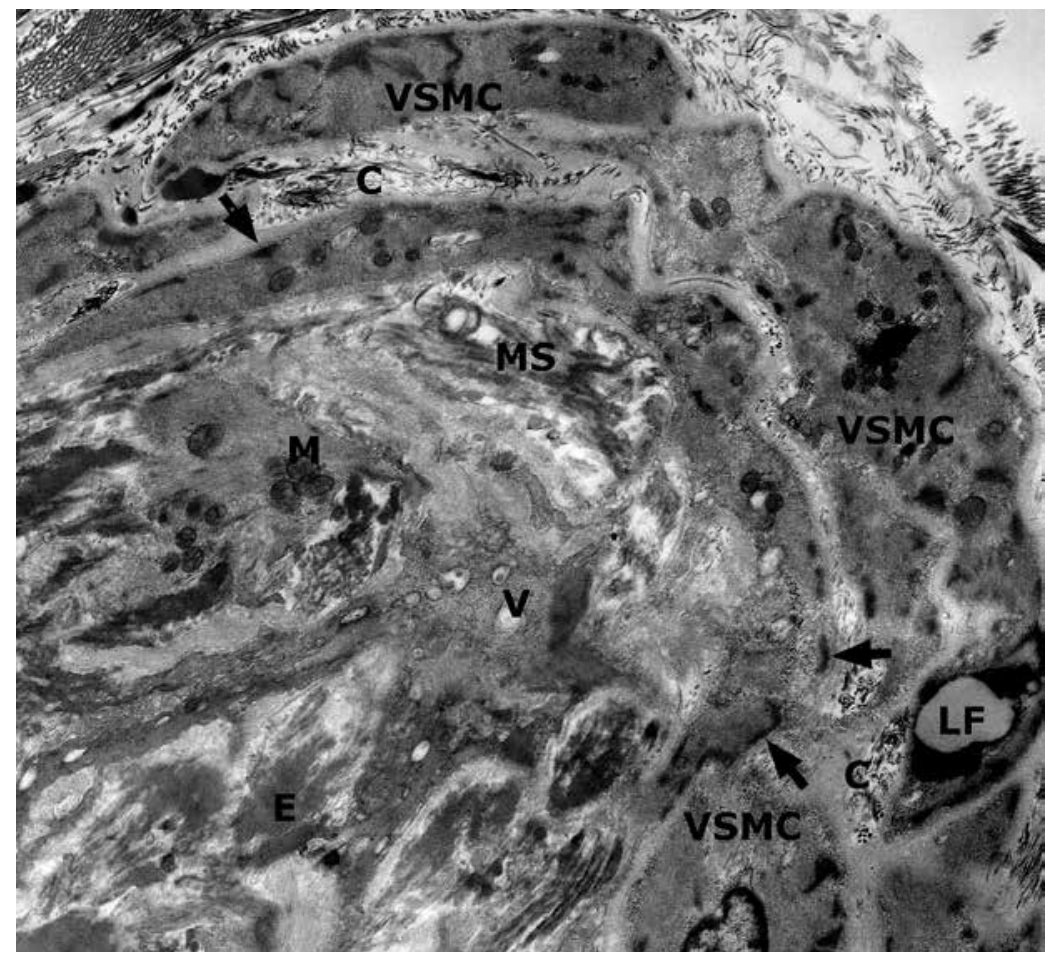

Fig. 6. Degenerative changes in arteriolar wall. Different size and shape of vascular smooth muscle cells (VSMC) with lipofuscin (LF), prominent dense bodies (arrows), vacuole (V) and dense or swollen mitochondria (M). In irregular thickened basement membrane deposits of elastin (E), collagen (C) and mucosubstances (MS) are visible. Orig. magn. $\times 4400$.

The mitochondria were often swollen and grouped in clusters or very numerous mitochondria filled the whole cell (Fig. 7B). Numerous VSMCs exhibited misshapen nuclei and well-marked dense bodies (Fig. 7C, 7D).

In some VSMCs, abundant, large deposits, demonstrating fingerprint profiles, were visible. The majority of these deposits showed mixed complexes of fingerprint and curvilinear profiles together with lipofuscin (Fig. 8A). In the cytoplasm of VSMCs with deposits, only a few organelles, mainly clusters of mitochondria, were present (Fig. 8A, 8B).

The wall of arterioles was markedly damaged. In the thickened basement membrane numerous collagen fibres, a large amount of elastin, "pigtails" of mucosubstances and clumps of non-specific granular debris were noted (Fig. 6, 7C, 7D). Hyaline material was also visible in some parts of arteriolar walls (Fig. 7C).

\section{Discussion}

The 84-year-old patient did not show typical clinical features of CADASIL. A detailed description of clinical condition of the patient is presented in our earlier paper [ 3 in press]. The patient was tested for CADASIL because his son had previously been diagnosed with this disease on the basis of ultrastructural and genetic examination [17]. Genetic testing of both father and son showed the same mutation in exon 12 of the NOTCH3 gene; however, the picture of vascular pathology was different. In the CADASIL patient presented in this paper, all the capillaries were negative for GOM deposits although their basement membrane was thickened and mural cells were degenerating and disappearing. In the extreme state only the looped basement membrane with remnants of cells was visible. The capillaries of his son revealed GOM deposits occasionally, but in his arterioles very numerous typical GOM deposits were visible [17]. In contrast, in the present CADASIL patient, GOM deposits were observed only in arteriolar walls, but they were rare and sometimes difficult to identify because they were less osmiophilic and granular.

This is consistent with the observation made by Brulin et al. [2] that in some elderly CADASIL patients 

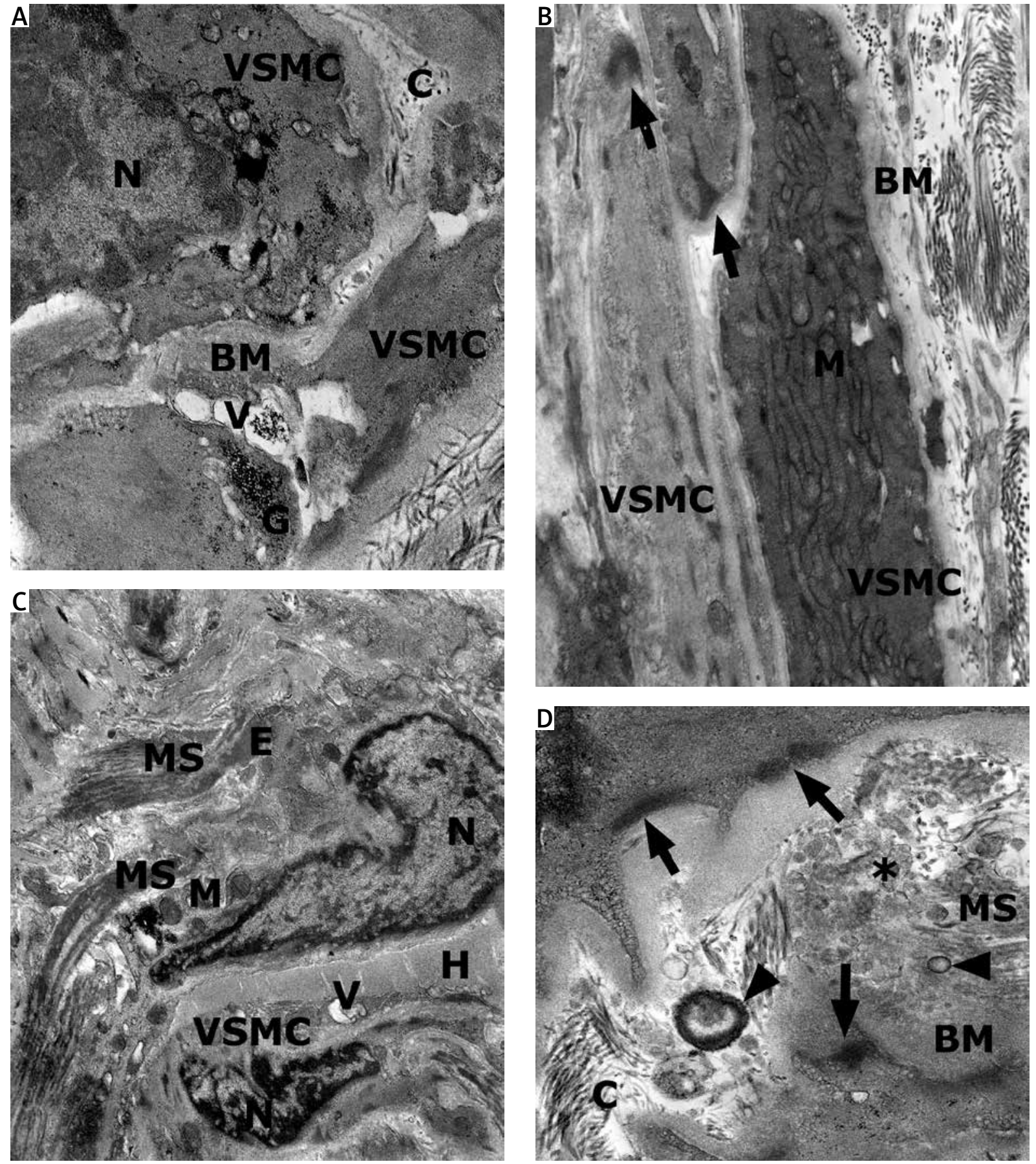

Fig. 7. Different degenerative changes of vascular smooth muscle cells (VSMC) and basement membrane (BM). A) VSMC with numerous vacuoles (V) or swollen mitochondria (M) and glycogen (G). Nucleus (N), collagen (C). Orig. magn. $\times 12$ 000. B) VSMC filled with numerous mitochondria (M) with different morphology or with prominent dense bodies (arrows). Basement membrane (BM). Orig. magn. $\times 7000$. C) VSMC with misshapen nucleus $(\mathrm{N})$, vacuole $(\mathrm{V})$. Between VSMC, hyaline $(\mathrm{H})$, elastin (E) and mucosubstances (MS) deposits are visible. Orig. magn. $\times$ 4400. D) Single deposits of extracellular calcium (arrowheads) in the degenerated basement membrane (BM), collagen (C), mucosubstances (MS) and numerous debris of different morphology (asterisk). Prominent dense bodies (arrows) at surface of VSMC. Orig. magn. $\times 12000$. 

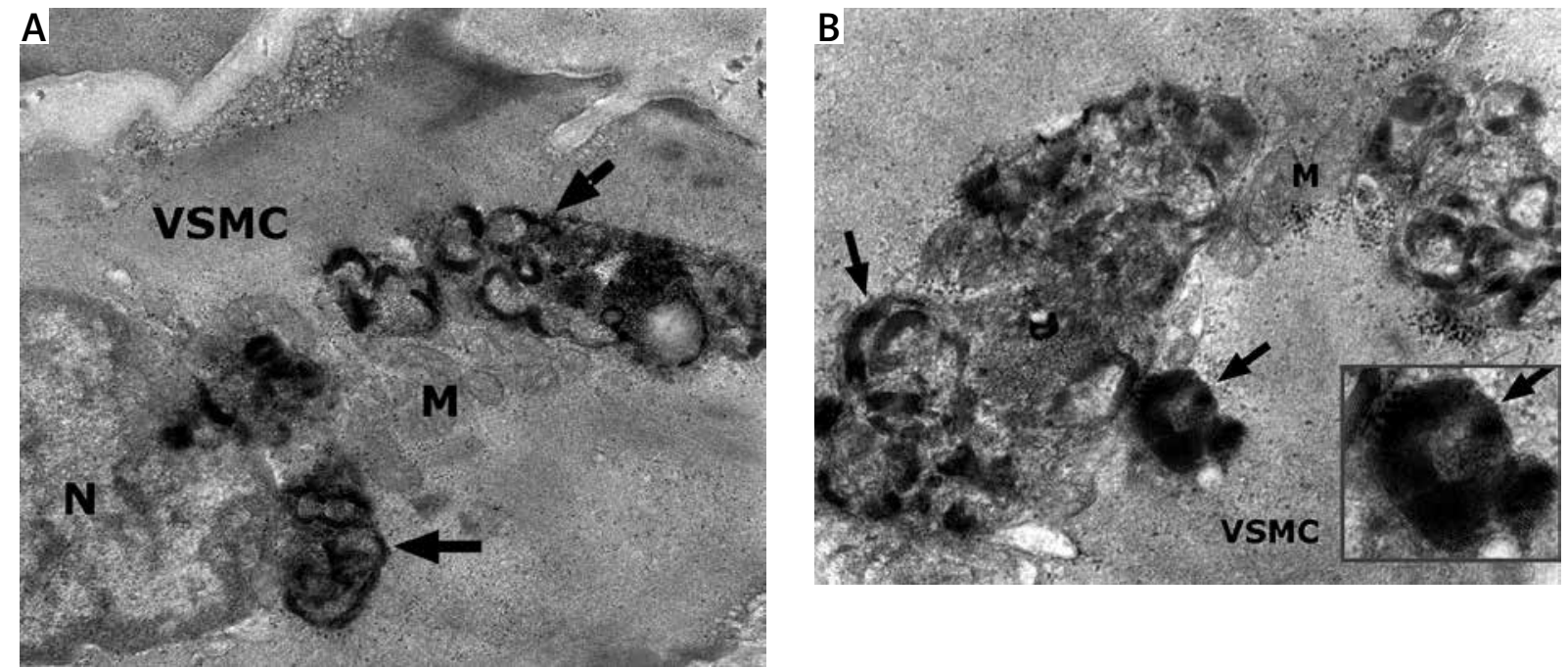

Fig. 8. A) Mixed fingerprint and curvilinear profiles (arrows) located in vascular smooth muscle cells (VSMC). Nucleus (N), mitochondria (M). Orig. magn. $\times 12$ 000. B) Higher magnified fingerprint and curvilinear profiles (arrows). In the inset higher magnification of fingerprint deposits. Orig. magn. $\times 20000$.

GOM become rare and difficult to identify. They also demonstrated that the highest numbers of GOM deposits per vessel and per patient were found in CADASIL patients at the age around 50 years. In elderly patients (65-75 years) the mean number of GOM deposits per vessel and per patient decreased. Similarly, a small amount of GOM was present in a 19-year-old patient [13]. It is known that GOM deposits are composed of 10-15 nm granules, but their morphological picture varies, including size, shape and electron density $[14,18,22,26]$, which may suggest that they undergo changes. Based on our observations together with morphometric analysis of the age-related mean number of GOM deposits per skin vessel [2] and early reports [22,26], it can be suggested that GOM deposits disappear, which could lead to the decreased number of GOM deposits in elderly patients. On the other hand, vessels in a human fetus with a Notch 3 mutation did not contain GOM deposits, and morphology of VSMCs, as well as other vascular wall structures, was normal, which suggests that the vessel wall abnormalities are initiated and progressed in the course of the first two decades of life [16]. In a 19-year-old CADASIL patient, only a small amount of GOM deposits was visible [13].

Although a small number of GOM deposits was found in our patient, electron microscopy revealed severe and common changes in arterioles, including VSMCs, endothelial cells and basement membrane.
Endothelial cells in our material exhibited changes similar to those previously described in CADASIL patients [2,23].

The pathology of VSMCs varied greatly. They showed differences in size, shape and degenerative changes, including their loss. The degeneration and loss of VSMCS is a typical feature of CADASIL arterioles [2,21,25]. In the oldest patients (aged 55-65 years), VSMCs were totally destroyed [21]. In our patient, in general, VSMCs contained only a few organelles, but some differences were observed between cells.

Some of the VSMCS were filled by numerous and closely packed mitochondria with abnormal ultrastructure while others contained only a few mitochondria or clusters of distended mitochondria. It has been previously demonstrated that the mean number of abnormal mitochondria was higher in VSMCs in CADASIL as compared to control cells, which might have an effect on vital cellular functions important for CADASIL pathology [27]. The ultrastructural picture of the degenerating VSMCs demonstrates different numbers and morphology of mitochondria; therefore, it may be assumed that the mechanisms of the degeneration process may also differ in these cells. The presence of lysosomal inclusions in VSMCs with fingerprint profiles was a very interesting observation. Some of them revealed mixed morphology. Those inclusions are observed in neuronal ceroid lipofuscinosis, but they were also found in 
skeletal muscles in "fingerprint body myopathy" [9]. The interpretation of their presence in VSMCs of our patient is difficult, especially since they seem to be non-specific.

Electron microscopy analysis of an arteriolar wall revealed the presence of collagen fibres, elastin, hyaline, mucosubstances and different granular debris in basement membrane probably derived from massive degeneration of VSMCs. These findings have been described both in CADASIL pathology and the aging process $[2,6,13,20]$. In irregularly thickened subendothelial space, large aggregates mainly of elastin were observed. In CADASIL patients, increased production of elastin [4], as well as fibrous and hyaline thickening of the vessel walls, was observed $[6,24]$. On the other hand, hyaline is observed in different processes, such as aging and hypertension [20], and it is not specific for CADASIL pathology such as collagen fibres usually visible in the form of clusters scattered throughout the basement membrane of our patient.

It is important that our patient was diagnosed at the age above 80 . It should also be remembered that vascular pathology probably results from typical CADASIL and age-related pathologies. The patient diagnosed with CADASIL at an advanced age showed minimal symptoms, in contrast to his son [17], as well as a different picture of vascular pathology and in particular the number and morphology of GOM deposits. This indicates that a clinical phenotype, such as vascular pathology, may be different despite the same mutation. The reason remains an open question.

\section{Acknowledgments}

This study was supported by grant NN402375039 from the Polish Ministry of Science and Higher Education.

\section{Disclosure}

Authors report no conflict of interest.

\section{References}

1. Benabu Y, Beland M, Ferguson N, Maranda B, Boucher RM Genetically proven cerebral autosomal-dominant arteriopathy with subcortical infarcts and leukoencephalopathy (CADASIL) in a 3-year-old. Pediatr Radiol 2013; 43: 1227-1230.

2. Brulin P, Godfraind C, Leteurtre E, Ruchoux MM. Morphometric analysis of ultrastructural vascular changes in CADASIL: analysis of 50 skin biopsy specimens and pathogenic implications. Acta Neuropathol 2002; 104: 241-248.
3. Buczek J, Gramza K, Lewandowska E, Błażejewska-Hyżorek B, Kurkowska-Jastrzębska J. CADASIL - opis przypadku osiemdziesięcioletniego pacjenta z niewielkimi objawami klinicznymi choroby. Medycyna Praktyczna - Neurologia [in press].

4. Caronti B, Calandriello L, Francia A, Scorretti L, Manfredi M, Sansolini T, Pennisi EM, Calderaro C, Palladini G. Cerebral autosomal dominant arteriopathy with subcortical infarcts and leucoencephalopathy (CADASIL) Neuropathological and in vitro studies of abnormal elastogenesis. Acta Neurol Scand 1998; 98 : 259-267.

5. Cleves C, Friedman NR, Rothner AD, Hussain MS. Genetically confirmed CADASIL in a pediatric patient. Pediatrics 2010; 126: 1603-1607.

6. Davous P. CADASIL: a review with proposed diagnostic criteria. Eur J Neurol 1998; 5: 219-233.

7. Dichgans M, Mayer M, Uttner I, Brüning R, Müller-Höcker J, Rungger G, Ebke M, Klockgether T, Gasser T. The phenotypic spectrum of CADASIL: clinical findings in 102 cases. Ann Neurol 1998; 44: 791-839.

8. Dziewulska D, Lewandowska E. Pericytes as a new target for pathological processes in CADASIL. Neuropthol 2012; 32: 515521

9. Engel AG, Angelini C, Gomez MR. Fingerprint body miopathy. Mayo Clinic Proceedings 1972; 47: 377-388.

10. Golomb MR, Sokol DK, Walsh EL, Christensen CK, Garg BP. Recurrent hemiplegia, normal MRI, and NOTCH3 mutation in a 14-yearold: Is this early CADASIL? Neurology 2004; 22: 2331-2332.

11. Granild-Jensen J, Jensen UB, Schwartz M, Hansen US. Cerebral autosomal dominant arteriopathy with subcortical infarcts and leukoencephalopathy resulting in stroke in an 11-year-old male. Dev Med Child Neurol 2009; 51: 754-757.

12. Hartley J, Westmacott R, Decker J, Shroff M, Yoon G. Childhood-onset CADASIL: clinical, imaging, and neurocognitive features. J Child Neurol 2010; 25: 623-627.

13. Kalimo H, Miao Q, Tikka S, Mykkänen K, Junna M, Roine S, Viitanen M, Pöyhönen M, Baumann M. CADASIL: the most common hereditary subcortical vascular dementia. Future Neurol 2008; 3: 683-704.

14. Lačković V, Bajčetič M, Šternić N, KoskićV, Zidverc J, Pavlović A, Lačković M, Kočica M. Ultrastructural analysis of small blood vessels in skin biopsies in CADASIL. Arch Biol Sci 2008; 60: 573-580.

15. Lee YC, Yang AH, Soong BW. The remarkably variable expressivity of CADASIL: report of a minimally symptomatic man at an advanced age. J Neurol 2009; 256: 1026-1027.

16. Lesnik Oberstein SAJ, Maat-Schieman MLC, Boon EMJ, Haan J, Breuning MH, van Duinen SG. No vessel wall abnormalities in a human foetus with a NOTCH 3 mutation. Acta Neuropathol 2008; 115: 369-370.

17. Lewandowska E, Wierzba-Bobrowicz T, Buczek J, Gromadzka G, Dziewulska D. CADASIL patient with extracellular calcium deposits. Folia Neuropathol 2013; 51: 302-311.

18. Lewandowska E, Dziewulska D, Parys M, Pasennik E. Ultrastructure of granular osmiophilic material deposits (GOM) in arterioles of CADASIL patients. Folia Neuropathol 2011; 49: 174-180.

19. Mourad A, Levasseur M, Bousser MG, Chabriat H. CADASIL with minimal symptoms after 60 years. Revue Neurologique 2006; 162: 827-831. 
20. Pavelka M, Roth J. Collagen and elastic fibres. In: Functional Ultrastructure Atlas of tissue biology and pathology. $2^{\text {nd }}$ ed. Springer-Verlag, Wien 2010; pp. 278-279.

21. Ruchoux MM, Guerouaou D, Vandenhaute B, Pruvo JP, Vermersch P, Leys D. Systemic vascular smooth muscle cell impairment in cerebral autosomal dominant arteriopathy with subcortical infarcts and leucoencephalopathy. Acta Neuropathol 1995; 89: 500-512.

22. Ruchoux MM, Maurage CA. CADASIL: Cerebral autosomal dominant arteriopathy with subcortical infarcts and leukoencephalopathy. J Neuropathol Exp Neurol 1997; 56: 947-964.

23. Ruchoux MM, Maurage CA. Endothelial changes in muscle and skin biopsies in patients with CADASIL. Neuropathol Appl Neurobiol 1997; 23: 60-65.

24. Schröder JM, Sellhaus B, Jörg J. Identification of the characteristic vascular changes in a sural nerve biopsy of a case with cerebral autosomal dominant arteriopathy with subcortical infarcts and leukoencephalopathy (CADASIL). Acta Neuropathol 1995; 89: 116-121.

25. Schröder JM, Züchner S, Dichgans M, Nagy Z, Molnar MJ. Peripheral nerve and skeletal muscle involvement in CADASIL. Acta Neuropathol 2005; 110: 587-599.

26. Tikka S, Mykkänen K, Ruchoux MM, Bergholm R, Junna M, Pöyhönen $M$, Yki-Järvinen $H$, Joutel $A$, Viitanen $M$, Baumann $M$, Kalimo H. Congruence between NOTCH3 mutations and GOM in 131 CADASIL patients. Brain I Neurol 2009; 132: 933-939.

27. Viitanen M, Sundström E, Baumann M, Poyhonen M, Tikka S, Behbahani H. Experimental studies of mitochondrial function in CADASIL vascular smooth muscle cells. Exp Cell Res 2013; 319: 134-143. 